\title{
Peer led Aboriginal parent support: Program Development for Vulnerable Populations with Participatory Action Research
}

\section{Authors}

Ailsa Munns, Bachelor Applied Science (Nursing), Master Nursing, PhD Candidate. Lecturer, School of Nursing, Midwifery \& Paramedicine, Faculty of Health Sciences, Curtin University, Western Australia.

Christine Toye, PhD, Associate Professor, Older Persons' Health Care, School of Nursing, Midwifery \& Paramedicine, Faculty of Health Sciences Curtin University, Western Australia.

Desley Hegney, Dip Nurs Edu, B.A. (Hons1), PhD, FCNA. Professorial Research Fellow, Research Division, Central Queensland University, Queensland; Hon. Professor, School of Nursing and Midwifery, University of Southern Queensland, Queensland; Adjunct Professor, School of Nursing, University of Adelaide, South Australia.

Marion Kickett, PhD. Professor, Director of Centre for Aboriginal Studies, Curtin University, Western Australia.

Rhonda Marriott, PhD, Professor, Aboriginal Health and Wellbeing, School of Psychology and Exercise Science, Murdoch University, Western Australia; Adjunct Professor, Centre for Child Health Research, The University of Western Australia; Chair in Nursing, Maternal \& Newborn Health, Aboriginal Health \& Wellbeing, Nursing and Midwifery Office, Department of Health Western Australia.

Roz Walker, BA (Hons), PhD, Associate Professor, Head, Aboriginal Maternal Health and Child Development, and previously Chief Investigator, NHMRC, Centre for Research Excellence in Aboriginal Health and Wellbeing, Telethon Kids Institute, Western Australia; University of Western Australia, Western Australia.

Corresponding author:

Ailsa Munns

School of Nursing, Midwifery \& Paramedicine

Curtin University

GPO Box U1987, Perth, Western Australia, 6845

Phone: 0892662209

Email: A.Munns@curtin.edu.au

Acknowledgements

Our thanks are extended to the Peer Support Workers, Project Coordinator and Education Support Officer (Ngala) who generously gave their time and support to the parent support project. Thanks are also given to Ngala management.

This work was supported by the NHMRC, Centre for Research Excellence in Aboriginal Health \& Wellbeing at Telethon Kids and the Western Australian Nurses Memorial Charitable Trust. 


\section{Abstract}

Background: Participatory action research is a credible, culturally appropriate methodology that can be used to effect collaborative change within vulnerable populations.

Aim/Objective: This participatory action research study was undertaken in a Western Australian metropolitan setting to develop and evaluate the suitability, feasibility and effectiveness of an Aboriginal peer-led home visiting program. A secondary aim, addressed in this paper, was to explore and describe research methodology used for the study and provide recommendations for its implementation in other similar situations.

Methods: Participatory action research using action learning sets was employed to develop the parent support program and data addressing the secondary, methodological aim were collected through focus groups using semi-structured and unstructured interview schedules. Findings were addressed throughout the action research process to enhance the research process.

Results: The themes that emerged from the data and addressed the methodological aim were the need for safe communication processes; supportive engagement processes and supportive organisational processes.

Conclusions: Aboriginal Peer Support Workers and community support agencies identified three important elements central to their capacity to engage and work within the participatory action research methodology. This research has provided innovative data, highlighting processes and recommendations for child health nurses to engage with the Peer Support Workers, parents and community agencies to explore culturally acceptable elements for an empowering methodology for peer-led home visiting support. There is potential for this nursing research to credibly inform policy development for Aboriginal child and family health service delivery, in addition to other vulnerable population groups. Child health nurses/researchers can use these new understandings to work in partnership with Aboriginal communities and families to develop empowering and culturally acceptable strategies for developing Aboriginal parent support for the early years. 


\section{Impact Statement}

Child health nurses and Aboriginal communities can collaborate through participatory action research to develop peer-led support for the early years.

Keywords: Participatory Action Research, action learning sets, program development, peerled parenting support, Aboriginal parent support

Indigenous Australian peoples are people who identify as Aboriginal or Torres Strait Islander. Respectfully, throughout this paper, they will be described as Aboriginal. 


\section{Introduction}

The confidence of Aboriginal families to provide positive environments for their children's developmental health is increasingly recognised as fundamental to lifelong wellbeing, educational and employment opportunities. Positive family environments supporting children's growth and development are influenced by a range of psychosocial circumstances (Zubrick et al., 2014), such as mental health and poverty. Therefore, there is a need for evidence based innovative strategies to address these complex social determinants of health, in particular, informing support that community child health nurses offer to Aboriginal families. Exploring the types of programs and engagement strategies that these nurses use with parents is vital (Schaffer, Keller \& Reckinger, 2015), as they guide culturally relevant service delivery.

However, use of inappropriate methodologies that cannot take into account life complexities of vulnerable population groups may misrepresent findings and compromise research for social change. Cultural and psychosocial realities for under-served families and communities reflect the need to protect their values, beliefs and worldviews, requiring researchers to refocus from traditional inquiry methods to those which work in partnership with participants to generate relevant and meaningful outcomes (Wilson \& Neville, 2009). Positive researcher engagement with Aboriginal families is vital for results to be significant and meaningful for parents and children, and their wider community. Aboriginal people have identified issues of trust, credibility and worth, in relation to both researchers and research, as impacting on outcomes of value to them and Aboriginal society. Additionally, the extent to which they are equal participants with non-Aboriginal researchers is crucial to relevant outcomes, but more understanding is needed in developing their research participation and capacity building (Hunt, 2013).

A recent systematic review identified that effective partnerships between researchers, Aboriginal community members and service providers support Aboriginal people's participation in research, thereby improving quality of the investigations (Snijder et al., 2015). Furthermore, Bainbridge et al. (2015) emphasise the need for non-Aboriginal researchers to engage with Aboriginal people to increase the meaningfulness, applicability and sustainability of research by taking into consideration Aboriginal ethics and values. Incorporating Aboriginal knowledge systems within participatory action research (PAR), can be transformative for participants and researchers (Wright, 2011). 
There are global recommendations for increased focus on how research methodology may be used to bring about improvements in Aboriginal health (Sanson-Fisher et al., 2006).

International recognition of context on health research priorities and outcomes highlights the importance of appropriate methodologies to explore everyday challenges to Aboriginal health and wellbeing (Adelson, 2005; Campbell et al., 2007). Investigation into relevant critical paradigms and methodologies within Aboriginal populations is essential.

PAR is a methodology enabling engagement of community participants to ensure research integrity (Hegney \& Francis, 2015), which is of particular relevance when investigating Aboriginal health and wellbeing. Australian Aboriginal peoples are the first inhabitants, with self -identification, community acceptance and ancestry significant to their identity (AHRC, 2017).

\section{Background}

An Australian remote area Aboriginal parent support program utilised PAR with emerging positive outcomes (Munns \& Walker, 2015). As there is limited evidence on culturally appropriate assistance for Aboriginal parents and culturally acceptable ways of identifying meaningful evidence in urban child health practice (Munns et al., 2016), a study was commenced in 2013 by a non-Aboriginal child health nurse researcher in an outer metropolitan region of Western Australia (WA).

During 2013, a WA non-government family support agency collaborated with the researcher to work with an Aboriginal urban community to explore new culturally acceptable strategies for engaging with Aboriginal parents and peer support workers (PSWs) to develop home visiting parent support. This low socio-economic community had well recognised adverse social determinants of health (ABS, 2011).

\section{Aim}

This PAR research study was undertaken in a WA metropolitan setting to develop and evaluate the suitability, feasibility and effectiveness of an Aboriginal peer-led home visiting program. A secondary aim, addressed in this paper, was to explore and describe the research methodology used for the study and provide recommendations for its implementation in other similar situations.

Ethics approvals were granted by the WA Aboriginal Health Ethics Committee and the University’s Human Research Ethics Committee. 


\section{Paradigm}

PAR sits within a critical social theory paradigm, enabling researchers to better understand and help Aboriginal parents navigate sociocultural, economic and relational life experiences. PAR fosters self-reflection for both researchers and participants on how social position influences parents' everyday perceptions of reality, access to resources and empowering action within their community (McDowell, 2015; Habermas, 1984).

\section{Methodology}

In collaboration with study participants and an expert Aboriginal steering group (CREAHW), PAR was identified as the most appropriate methodology for the program's development. The program was based on connections between cycles of planning, acting, reflection, learning from their experiences and further action planning (Hegney \& Francis, 2015). The researcher collaboratively engaged participants in exploring their own needs and directions (Roberts \& Taylor, 2002). Interpreting these explorations and learnings was guided by participants' worldview beliefs and feelings (Denzin \& Lincoln, 2011). PAR differs from more traditional research approaches where participants are viewed as passive recipients of research outcomes (Baum, MacDougall \& Smith, 2006), often resulting in non-sustainability of community research. Figure 1 identifies the PAR model underpinning the program outline and methods. 


\section{Pre-study phase}

Program request from agency; Establish processes with agency, Meet community agencies, Recruit PSWs

\section{Participatory Action Research Cycle}

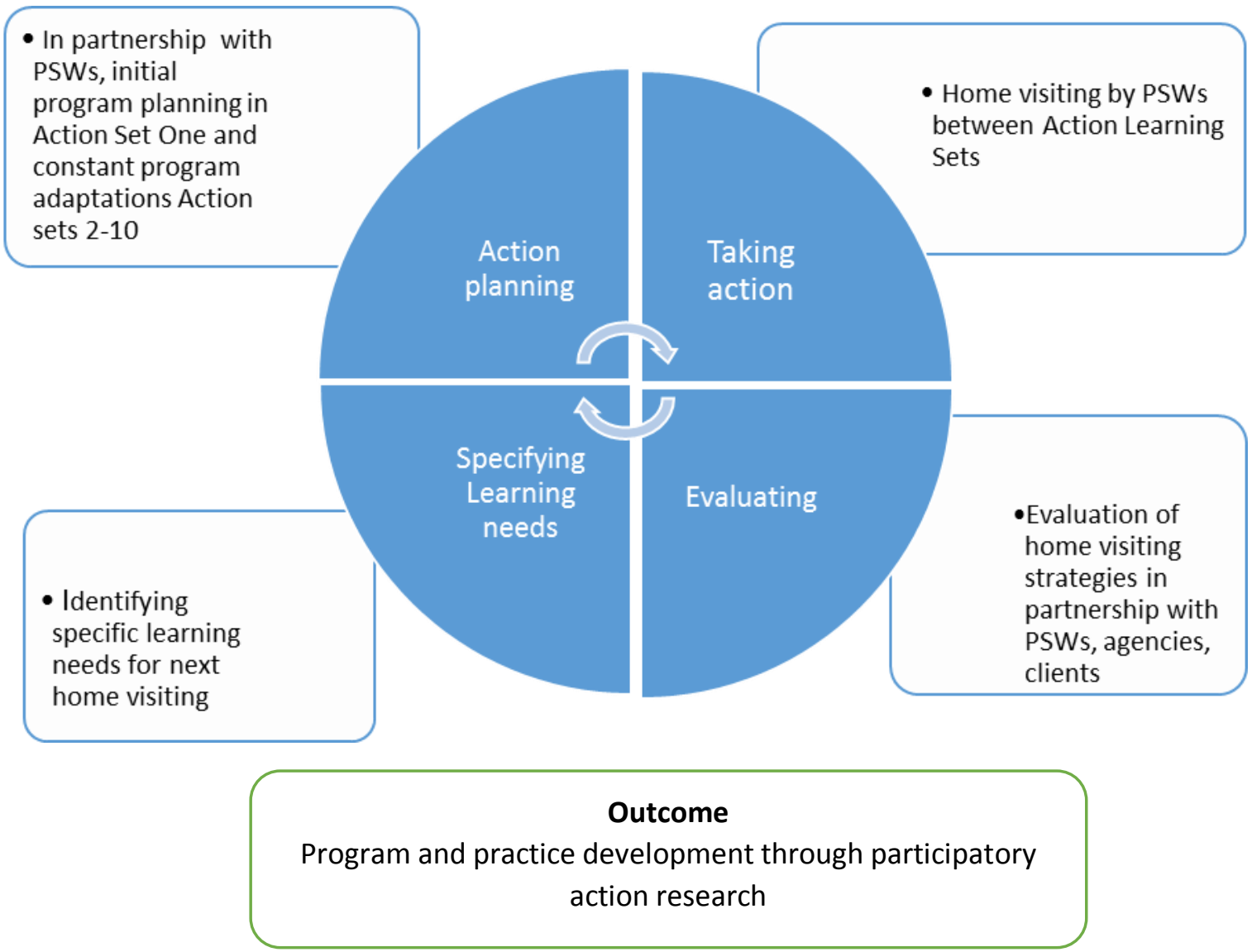

Figure 1: Participatory Action Research Model (Adapted, Susman \& Evered, 1978; Sullivan et al., 2013; Munns et al., 2016) 
Flexibility is a key PAR feature, enabling program modification with outcomes of cumulative learning, capacity building and elements of participant empowerment. Therefore, PAR is a relevant collaborative research approach, especially in Aboriginal communities, being beneficial when focusing on complex inequalities in this marginalised population (Baird et al., 2015). In all research, but particularly in Aboriginal research, a partnership model is fundamental to participants becoming researchers, holding equal power in research teams (Baum et al., 2006), enabling local knowledge to be used to develop realistic, achievable goals and strategies (Turner, 2002).

Internationally, PAR is recognised as a culturally sensitive, respectful and appropriate methodology for Indigenous populations (Herbert, 1996; Davis \& Reid, 1999). It has been implemented in a variety of Australian regions, providing opportunities for inclusion of stakeholder worldviews and redressing power imbalances between researchers and Aboriginal participants through encouraging active research partnerships, self-determination, capacity building and empowerment (Pyett, 2002; Henry et al., 2002).

Despite the rhetoric about PAR suitability within Aboriginal communities, searches for published evidence relating to use of PAR methodology to implement Aboriginal peer-led, home visiting parent support located only one paper which is from previous research by two of this study's authors (Munns \& Walker, 2015). PAR presents a strengths-based research approach, with recognised challenges. Grant, Nelson \& Mitchell (2008) identified five categories of factors impacting on PAR studies, outlined below: building relationships; acknowledging and sharing power; encouraging participation; making change and establishing credible accounts.

\section{Building relationships}

Long-term collaborative relationships between researchers and communities are needed to build trust and are dependent upon researcher skills and reflexivity, emotional involvement from all participants and joint resolutions of role conflicts. Reflexivity necessitates nonAboriginal researchers to critically evaluate how their values and assumptions impact their perspectives on client self-identified needs, health and wellbeing strategies (Crane \& O’Regan, 2010).

\section{Acknowledging and sharing power}

Enhancing genuine processes for meaningful research requires researchers to recognise unequal researcher-participant power relationships and need to relinquish leadership control 
usually evident in the research team leader role (Gray, Fitch, Davis \& Phillips, 2000; Walker, Schultz \& Sonn, 2014).

\section{Encouraging participation}

Barriers impacting on engagement processes with community members include: research timeline constraints (Gray et al., 2000); changes in personal or family circumstances of the research team; divided or indifferent interest by participants to the perceived research benefits (Queensland Government, DoC, n.d.); feelings of being overwhelmed or intimidated by community “outsiders" (Gray et al., 2000); and low self-efficacy of non-academic research team members (Rosenthal \& Khalil, 2010).

\section{Making change}

Potential for conflict exists between researchers and participants on the nature and time taken to achieve change (Grant et al., 2008). Conflicting and unrealistic expectations by researchers for helping people gain some control over their lives within complex disempowering environments can be problematic (Rosenthall \& Khalil, 2010).

\section{Establishing credible accounts}

Research needs to explore participants' experiences, recognising their co-construction of knowledge that is jointly developed to include shared interpretations. This develops credible and meaningful participant and researcher understandings.

Incorporating these categories within PAR methodology encouraged this non-Aboriginal researcher to engage in culturally reflective practice (Rix, Barclay \& Wilson, 2014; Walker et al., 2014), critically examining the relationship through self-reflection in collaboration with all participants. Structural positioning in relation to historical influences, such as negative impacts of colonial legacies, and contemporary issues, recognised sociocultural and socioeconomic effects from ongoing intergenerational trauma (Pihama et al., 2014; Dudgeon et al., 2014; Redman-MacLaren \& Mills, 2015), allowing multifaceted aspects to be explored together.

In this study, a complex web of social determinants of health highlighted the need for engagement with a range of research partners (Baird et al., 2015). Following the partner agency's identification of need for parent support, four steps were collaboratively planned for PAR implementation: development of a plan of critically informed action; acting on implementing the plan; observing effects of critically informed action in the context in which 
it occurred; and reflection and evaluation on these effects as a basis for further planning and critically informed action. These steps were undertaken through a succession of cycles (Kemmis \& McTaggart, 1998, p. 10).

PAR requires effective engagement which is dependent on creating safe 'communicative spaces', and maintaining respectful interactions where participants are able to work in equal partnership (Bevan, 2013). This collaborative approach is supported by the classical theorist Habermas, whose critical social theory examined influential concepts of social action, from which he proposed legitimacy of non-professional understandings and knowledge (Habermas, 1984; Brand, 1990). Physical and conceptual communication spaces are of equal importance. The requirement for a mutually agreeable physical space facilitates feelings of safe discussion while conceptual spaces incorporate types of human encounters that enable or impede open and reciprocal involvement (Healey et al., 2008; de Souza, 2009).

Pursuit of change with Aboriginal communities is enhanced by using PAR methodology to guide critical issues related to program development, allowing participants to respond to their own identified aspirations in a variety of contexts. As such, the methodology is guided by these multifaceted and changing requirements.

\section{Method}

Design

Ten action learning sets (ALSs) were facilitated over a 13 month period in which participants collaboratively developed locally responsive home visiting parent support and capacity building strategies for parents and PSWs (Munns et al., 2016). ALSs are an integral PAR facilitating tool (Bergold \& Thomas, 2012; Sullivan, Hegney \& Francis, 2013), providing a formal structure for participants to meet regularly in small learning groups over a fixed program cycle to collaboratively discuss issues relevant to their workplace realities, undertaking program strategies between ALSs to address identified issues (Smith \& O’Neill, 2003). Positive findings have been reported in relation to peer support with sharing of experiences and identification of topics for discussion (Spurell, 2000). Emotional discomfort related to disclosure, biased opinions, perceptions of participant powerlessness and lack of management support for initiating and maintaining groups impact on successful outcomes, along with the ability of participants to maintain regular attendance (Douglas \& Machin, 2004; Lee \& Porteous, 2010). 


\section{Research population}

There were three participant cohorts.

1. Aboriginal PSWs, Program Coordinator and Education Support Officer; a non-Aboriginal parent support worker. The inclusion criterion was employment in the family support program, with no exclusion criteria.

2. Aboriginal clients. Inclusion criteria were engagement with PSWs and the presence of one or more children aged 0-4 years. The exclusion criterion was having no children aged 0-4 years.

3. Community agency staff. Inclusion criteria were provision of services either within or to the geographically area to assist Aboriginal families that met the inclusion criterion. The exclusion criterion was not having this purpose.

\section{Data collection}

To demonstrate flexibility needed for effective engagement, PAR utilises a non-prescriptive range of quantitative and qualitative data collection methods such as audits of document records, participant observation, semi-structured interviews and focus groups (Hegney \& Francis, 2015). ALSs were held four to six weekly, during which separate focus groups were conducted for all cohorts. PSW focus groups were conducted in every set where the researcher facilitated the participants' reflective practice, informing critical reviews of program strengths, challenges and interagency collaboration and the researcher's cultural reflexivity. Client and community agency focus groups were planned for sets one, four, seven and ten, relating to program benefits, challenges, PSW engagement and interagency collaboration. Responses from all cohorts contributed to collaborative planning for the next home visiting implementation cycle.

During the focus groups, qualitative data were collected, through a semi-structured group interview process for PSWs and community agency participants and an unstructured group interview process with clients (Cohen \& Crabtree, 2006). (Appendix A). These nonprescriptive approaches encouraged participants' ideas to be heard, offering potential for influencing change (Fredericks et al., 2010). The methodology and data collection processes provided opportunities for participants to reflect, present unique Aboriginal perspectives and have direct influence on program development. 

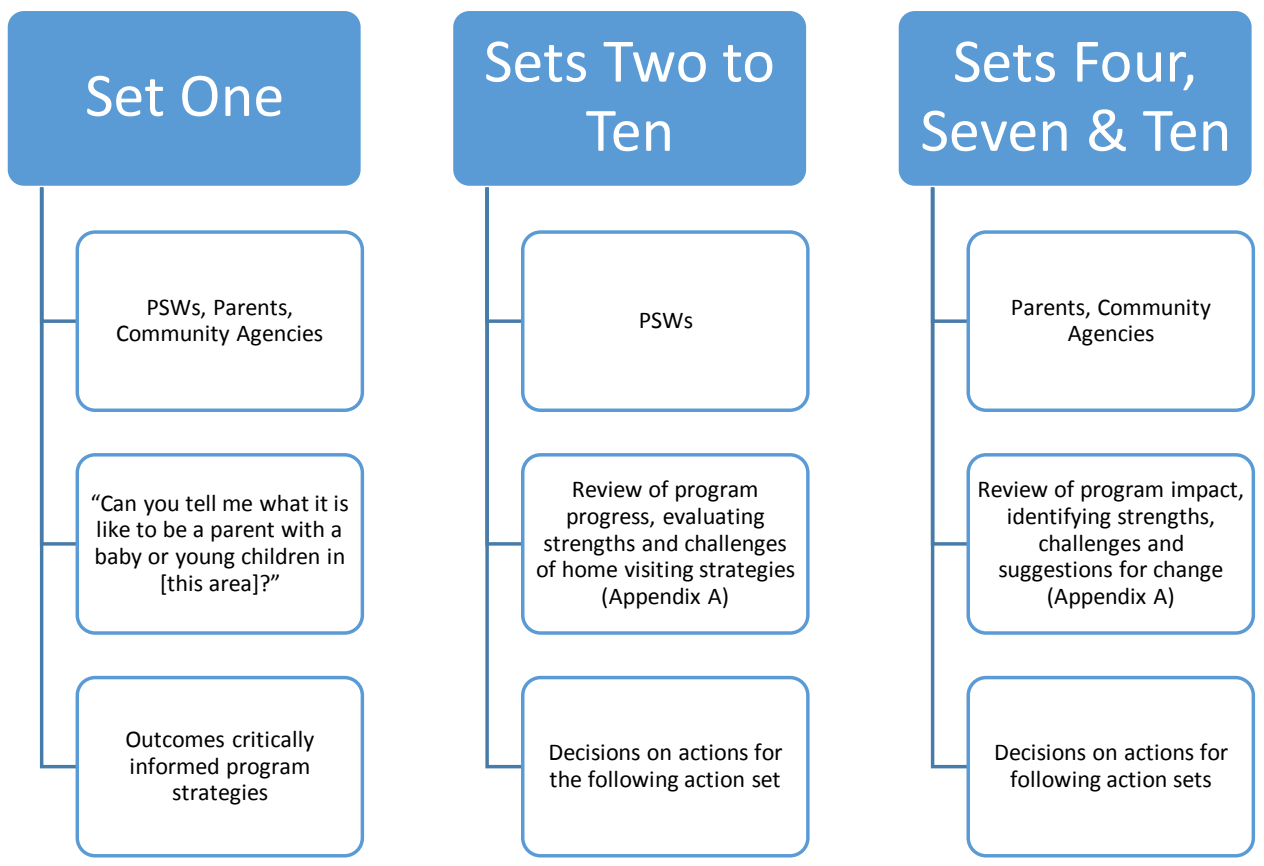

Figure 2: Focus Group Interviews in Action Learning Sets

Yarning is an Indigenous cultural form of conversation and was used as a data gathering tool during the unstructured client interview processes. (Bessarab \& Ng'andu, 2010; Bessarab, 2012). This is a rigorous and culturally safe data collection method and the preferred medium of interaction when Aboriginal people are research partners (Bessarab \& Ng'andu, 2010; Geia, Hayes \& Usher, 2013).

\section{Trustworthiness of data}

Mechanisms such as peer debriefings, member checks and audit trails were used for credibility, along with acknowledgement of known research limitations (Polit \& Beck, 2010). Reflective debriefings were used as member checks at the end of interviews for PSWs and parents. Follow up contact was problematic due to participant mobility, absence from work and PSW hesitancy in reviewing transcripts (Polit \& Beck, 2010).

Stability of research data over time and differing research conditions facilitated dependability, with data checks by academic supervisors. Confirmability was evidenced by data analysis similarities between the researcher and supervisors (Polit \& Beck, 2010). The researcher identified potential biases, documenting an audit trail providing transparency to method consistency, raw data, field notes and thematic analyses stages. The extent to which the research findings can be transferred to other settings correlates to research population similarities and alternate populations (Polit \& Beck, 2010), with sufficient data enabling 
research consumers to recognise relevance of findings to other contexts (Lincoln \& Guba, 1985).

\section{Data analysis}

Trusting, non-judgemental environments within ALSs provided rich data. Data were thematically analysed (Braun \& Clarke, 2006), allowing categorization, clustering and identification of common themes from research responses (Streubert Specziale \& Carpenter, 2003).

\section{Results and Discussion}

Demographic data

Approximately 21 study participants were anticipated; four Aboriginal PSWs, one Aboriginal Project Coordinator, one Aboriginal Education Support Officer (for three months), one nonAboriginal parent support worker (for four months), eight to ten client families and four informants from community agencies supporting parents in this community. Engaging families for interviews was difficult (Milroy, 2014) with only two being able to contribute data, resulting in 14 participants.

\section{Qualitative data}

Three research process themes emerged relating to PAR implementation within ALSs: safe communication processes; supportive engagement processes and supportive organisational processes. These are presented with participant exemplars giving voice to their responses.

\section{Safe communication processes ("We can have a bit of a chat")}

Safe physical spaces for discussion were identified by all participants, with acceptable emotionally protective conceptual communication spaces being dependent on a range of influences. For PSWs, ALSs were undertaken in relaxed meeting rooms away from their working office. PSWs freely shared information for two to three hours in each of their focus groups, discussing a range of sensitive topics such as domestic violence, alcohol and drug abuse, justice system clients and mental health issues.

I'll judge what the risk is, whether it's low, medium or high. That'll come down to if it's a domestic violence situation or drugs and alcohol, mental health. (Coordinator) 
However, they confidentially acknowledged declining relationships and trust with senior members of the PSW management team which contributed to less discussion and data availability from ALSs seven to ten.

Community agency staff requested interviews at their workplace. They appeared to be relaxed during conversations of one to two hours, enabling safe psychological environments where interviews often extended into confidential personal discussions on their own parenting styles.

Clients requested home interviews. The researcher addressed cultural protocols, demonstrating respect to the family by being introduced as a credible non-Aboriginal researcher by a PSW who also presented a gift such as children's books or healthy breakfast cereal. Following this, visits were undertaken alone.

It was our gesture of going on that first home visit, it is tricky that introduction. (PSW)

Issues of home visiting safety from partners with domestic violence histories necessitated phone interviews instead of face-to-face discussions.

It's going to be harder to see her when her partner's out [of jail]. (PSW)

Participants appreciated flexibility of place for focus groups, choosing convenient places for interviews which were then facilitated by the researcher in acceptable, non-threatening and non-judgemental environments. Complexities in Aboriginal families' lives were acknowledged, along with subsequent challenges for PSWs and community agencies in developing support strategies, which were not recognised in other existing programs.

What is realistic? [The program] is the only one offering a culturally appropriate service. (Aboriginal community agency worker)

Respecting participants as equal partners in the program development research was a significant feature, fostering long and informative discourses from PSWs and community agency staff. While parent interviews were short, there were relaxed exchanges of information covering a wide range of personal and community issues, demonstrating a nonjudgemental and empathic researcher approach. .

Openness within our team. Support of each other. Voicing ideas and frustrations. Communication best key to success. (Coordinator) 
Agreement was reached by the researcher and PSWs that focus group conversations would be respectfully acknowledged and discussed. This facilitated non-judgemental environments where PSWs raised issues, shared and practised home visiting strategies, explored their ideas to enhance the program and acknowledged challenges without fear of failure.

It's a good role play situation that you can look at and listen to, we can have a chat about it afterwards, what worked, what didn't work, what they observed and what they heard. (PSW) Adequate time was required for yarning as a cultural form of conversation. This narrative approach needed gradual facilitation to allow participants to give their distinct perspectives (Bessarab, 2012). Intermittent yarning was utilised by Aboriginal community agency staff and PSWs, indicating relaxed psychological environments.

A partnership approach enabled the researcher to reflect on discussions, recognising participants' complex psychocultural environments. Of note was the ability of community agencies to frame their interview responses through a cultural lens, enabling greater contextual insight into local challenges and strengths for Aboriginal parents.

Did the parents not get cuddles when they were young? Who brought the parents up? Were they from the Mission? (Aboriginal community agency worker)

With Aboriginal families, the family relationship is everything. (Aboriginal community agency worker)

These responses highlight parents' adverse experiences from historical Australian Aboriginal policies of forced removal from their families as children (Dudgeon \& Hirvonen, 2014).

Growing up in government or mission institutions had long-term effects sometimes resulting in poor psychosocial health outcomes (Hertzman, 2013).

The researcher's cultural reflexivity and acknowledgement of PSW's right of ownership of their version of parent issues and adversities appeared to facilitate their acceptance of the researcher and development of an equal partnership approach within the PAR process. This enhanced common understanding, intimacy and confidence within ALSs (Roer-Strier \& Sands, 2015), encouraging frank and valued conversations.

We need somebody to push this forward please, [Researcher], up there, because if it's not happening we have to quit. I'm saying this in front of all the girls. It has to go forward. $(P S W)$ 
Communication processes throughout various ALS stages were understanding of participants' physical and psychosocial needs. Supportive facilitating research processes required continuous review and adaptation, with time being an important underpinning factor. I think it's just become the normal now that we sit down and we'll talk about it. We just help each other as we go along... That's why it's going to work. (PSW)

\section{Supportive engagement processes ("It takes time to build relationships")}

PAR through ALSs facilitated positive engagement with PSWs and community agencies, with both cohorts willingly participating in focus groups.

[ALS] It was very, very valuable. (PSW)

There was $75 \%$ interview acceptance by community agencies in sets three and four due to prolonged illness and competing work commitments, with 100\% at other times. PSWs had intermittent absences through illness and family commitments. Use of yarning and researcher cultural reflexivity furthered participant engagement where their values and options for program development could be freely acknowledged and explored (Bessarab, 2012). PSWs also identified the value of PAR in enhancing their integrity.

(the ALSs) ...just to be able to say, "when I was doing my training", gives credibility to what you're doing. (PSW)

Despite positive anecdotal client feedback on the need for support, engagement of families within ALSs was problematic for a range of reasons. Researcher introductions to client families by PSWs were successful on two occasions. These families were available for interviews by the researcher at their homes, however, they only had two interviews each before moving from the area. Other clients were located opportunistically for support by PSWs at their homes, in the family support agency's office or elsewhere in the community, but due to a range of known and unknown factors, were unavailable for specific introductions or interview times as the researcher did not live or work in this community. As such, flexibility of place was available but not in relation to time.

There's lots of things going on with families. There's alcohol, drugs, looking after kids, proper housing, single mums, domestic violence, partners in jail. (PSW)

Contact may be very opportunistic or variable due to drugs, alcohol, homelessness.

(Community agency worker) 
Parents undertaking interviews expressed no difficulty with the PAR approach and were accepting of the researcher.

(Researcher: Can I call again) Yea, sure. (Parent)

The PAR framework enabled time for PSW reflections on practice, encouragement of skills and open, non-judgemental discussions.

We all know our strengths and weaknesses and help each other as we go along. (PSW)

How do they continue to engage with families who are constantly putting up barriers to receive help? What strategies can be used? Can we bring this to the next session so we can work together as a team? (Coordinator)

\section{Supportive organisational processes ("Given us encouragement”)}

There was positive organisational support for PSWs and community agencies to participate in PAR ALSs. Both partners scheduled time around client commitments. Due to compromised engagement processes, the researcher experienced difficulties with most attempts to interview clients. Organisational support was seen to enhance the ability of the methodology to engage as many participants as possible to be equal contributors to the development of home visiting peer support development.

This is really important because to build confidence in parents you have to have confidence yourself. You might know all this stuff but this [ALS discussion] is confirming a lot of things, formalising it. (PSW)

\section{Discussion}

All participants viewed PAR with ALSs as providing a culturally acceptable and accessible format from which they could contribute ideas and strategies for peer-led home visiting support. The aim of this paper was to explore and describe the research methodology used for the parent support program development, and provide recommendations for its implementation in other similar situations.

Participants identified safe communication processes as a key enabling feature of the methodology, where they could explore different approaches for the program in supportive, non-judgemental environments. Cultural reflexivity was paramount in interviews, facilitating insight into participant parenting perspectives and practices (Aronowitz et al., 2015; RedmanMacLaren \& Mills, 2015). Relinquishing direct leadership control enhanced continuous 
respectful interactions, enabling meaningful and beneficial data collection and parent support development (Dudgeon et al., 2014; Dawson \& Sinwell, 2012). Of note, was the use of yarning by PSWs, parents and some agency members which facilitated culturally safe discussion on their values and perspectives on early years support. Yarning is viewed as an empowering process by Aboriginal researchers (Fredericks et al., 2011) where understandings, program options and reflections can be examined in-depth without prejudice. Relinquishing direct leadership control enhanced continuous respectful interactions, enabling meaningful and beneficial data collection and parent support development (Dudgeon et al., 2014; Dawson \& Sinwell, 2012). This enhanced group trust, and accommodated participants' individual identities and impacting social environments (Bessarab, 2012; Ng'andu, 2004). Time was an important functional element of their communication.

Participants identified engagement with each other and the researcher as an important element of the methodology. Along with safe communication environments, regular work time to participate in ALSs were considered significant for fostering engagement, enabling them to reflect on practice, critique strategy strengths and challenges, and formulate further program development. However, several multilayered complexities contributed to challenging client engagement processes within this research framework which were identified by PSW and community agencies as being homelessness, transience, mental health, family issues and general life chaos, which is well established in the literature (Rosenthal \& Khalil, 2010; Milroy, 2014; Zubrick et al., 2014). These social determinants of health also contributed to clients' low self-efficacy and lack of capacity to undertake advance planning for ALS participation.

Additionally, it appeared that PSWs lacked confidence to give encouraging explanations to clients on the value of participating in ALSs. Developmental progress in their support role was influenced by a number of issues relating to being members of a disempowered population and experiencing concerns with PAR methodology, such as negotiating realistic expectations. Feelings of low self-efficacy and hesitancy with communication skills, particularly in not wishing to offend parents, resulted in caution with their parent engagement until they gained more experience and confidence (Grant et al., 2008; Rosenthal \& Khalil, 2010). Encouragement to participate in ALSs was always secondary to client issues, with PSWs at times not advocating for parent focus groups due to complexities of immediate family concerns and time required to manage them. This highlighted the need for flexible 
engagement of PSWs in their support role, over time developing confidence, teamwork and maintaining their focus through practice and peer and researcher support during ALSs.

Variable participant involvement is a common feature of PAR when used with vulnerable groups, potentially influencing establishment of reliable accounts (Grant et al., 2008) and posing challenges for PAR development. Complexities in acquiring consistent research data may never be fully understood by the researcher who, to ensure success, needs to be reflexive to participants' circumstances.

The practical aspect of researcher availability for ad hoc and opportunistic interview opportunities is a question of flexibility of time and place. Use of credible secondary data may assist in developing future strategies, such as information from PSWs who are members of the same community as clients. The ability of PSWs to be equal research partners with skills to interview clients opportunistically is recommended. Their competence for this role requires programs of educational support which would add to research costs and planning time. However, the ongoing capacity building would be beneficial to PSWs and their community for future program development relevant to their needs.

Collaborative partnerships developed through this methodology were integral in engaging participants and the researcher in long-term trusting relationships. PAR enabled more time for review of program strengths, challenges and collaborative strategies than in other research methodologies (Dentith et al., 2012; Rath, 2012). The ability of researchers to recognise and negotiate this issue has the potential to influence PAR integrity in the research process and quality of outcomes (Roberts \& Dick, 2003), thereby positively impacting on development of culturally relevant, acceptable and sustainable PSW strategies and outcomes.

Continuous respectful negotiations between the researcher and participants to facilitate collective approaches to data collection and action were facilitated by this methodology (Dawson \& Sinwell, 2012), developing an important emerging long-term element of research reliability and relevance. However, communication and organisational factors such as competing goal setting and lack of trust between group members can negatively influence the process.

Building relationships, encouraging participation and facilitating change in complex psychosocial environments through PAR is a long-term process needing organisational support (Grant et al., 2008; Rosenthall \& Khalil, 2010), which was recognised by participants as being fundamental to their participation. The regular participation time given to PSWs and 
community agency staff enhanced discussions and relationship development, program review and development of meaningful strategies. PSWs were also made available to assist the researcher with culturally appropriate parent introductions, thereby enhancing trust and quality of data from parent ALSs.

\section{Limitations}

With qualitative studies generally having small participant numbers, a potential weakness in the methodological approach can be identified (Mason, 2010). However, qualitative frameworks facilitated the researcher's close association and iteration with participants where issues and self-identified strategies were comprehensively explored (Crouch \& McKenzie, 2006).

Participants did not often comment on PAR methodology, but indicated acceptance with long interviews undertaken. Although this research was undertaken in a specific Australian urban Aboriginal community, the methodological data can inform use of PAR to facilitate program development in a range of other cultural and geographical settings.

While significant engagement issues with Aboriginal clients reduced data that may have further informed program improvements, the value of the two parent in-depth, descriptive responses and usefulness of data from the Aboriginal PSWs living in the same community as the clients, and being parents themselves, gives credence to their data analysis being aligned with parent responses.

\section{Impact Statement}

Community child health nurses, Aboriginal peer support workers, parents and their community can work in partnership through PAR to explore and develop culturally relevant parent support programs in the early years. The three elements integral to engaging and working within this research methodology have been identified as: safe communication processes; supportive engagement processes and supportive organisational processes.

\section{Conclusion}

There is little evidence on relevant research methodologies for early years support within Aboriginal populations. It is therefore vital that views of Aboriginal PSWs, parents and community agencies are heard to advance the use of PAR for development and implementation of culturally acceptable peer-led home visiting support. They have identified 
three important elements central to their capacity to engage and work within PAR: safe communication processes; supportive engagement processes and supportive organisational processes, recognising both enabling and challenging influences for research development. Significantly, adverse social determinants of health were recognised as impacting on participation through reducing participants' control over life events.

Creating environments for engaging program participants and identifying research data is challenging for researchers working with vulnerable populations. This research has provided innovative data, highlighting processes and recommendations for child health nurses to engage with Aboriginal PSWs, parents and community agencies to collaboratively define and explore culturally acceptable elements for an empowering methodology for peer-led home visiting support. There is potential for this nursing research to credibly inform policy development for Aboriginal child and family health service delivery, in addition to other vulnerable population groups, promoting culturally responsive and effective community health care. 


\section{References}

ABS (2007). Population distribution, Aboriginal and Torres Strait Islander Australians, 2006 (Cat No 4705.0). Canberra, ACT: Author. Retrieved from: http://www.abs.gov.au/AUSSTATS/abs@.nsf/DetailsPage/4705.02006

ABS (2011). Socio-economic indexes for areas (SEIFA) (Cat No 2033.0.55.001). Canberra, ACT: Author. Retrieved from: http://www.abs.gov.au/ausstats//DetailsPage/2033.0.55.0012011?OpenDocumentAustr $\underline{\text { alian }}$

ABS (2012). Census of Population and Housing - Counts of Aboriginal and Torres Strait Islander Australians, 2011 (Cat No 2075.0). Canberra, ACT: Author. Retrieved from http://www.abs.gov.au/ausstats/abs@.nsf/lookup/2075.0main+features32011

ABS (2014). Estimates and Projections, Aboriginal and Torres Strait Islander Australians, 2001 to 2026 (Cat No. 3238.0). Canberra, ACT: Author. Retrieved from: http://www.abs.gov.au/ausstats/abs@.nsf/Products/C19A0C6E4794A3FACA257CC90 0143A3D?opendocument

Adelson. N. (2005). The embodiment of inequity. Health disparities in Aboriginal Canada. Canadian Journal of Public Health, 96(Suppl. 2), S45-S61.

Aronowitz, R., Deen, A., Keene, D., Schnittker, J., \& Tach, L. (2015). Cultural reflexivity in health research and practice. American Journal of Public Health, 105(Suppl. 3), S403S408. http://dx.doi.org/10.2105/AJPH.2015.302551

Australian Human Rights Commission [AHRC] (2017). Questions and Answers about Aboriginal \& Torres Strait Islander Peoples. Retrieved from http://www.humanrights.gov.au/publications/questions-and-answers-about-aboriginaltorres-strait-islander-peoples

Bainbridge, R., Tsey, K., McCalman, J., Kinchin, I., Saunders, V., Watkin, L., Cadet-James, Y., Miller, A., \& Lawson, K. (2015). No one's discussing the elephant in the room: contemplating questions of research impact and benefit in Aboriginal and Torres Strait Islander Australian health research. BMC Public Health, 15(696), 1-10. http://dx.doi.org/10.1186/s12889-015-2052-3

Baird, M.B., Domain, E.W., Mulcahy, E.R., Mabior, R., Jemutai-Tanui, G., \& Filippi, M. (2015). Creating a bridge of understanding between two worlds: community-based collaborative-action research with Sudanese refugee women. Public Health Nursing, 32, 388-396. http://dx.doi.org/10.1111/phn.12172

Baum, F., MacDougal, C., \& Smith, D. (2006). Participatory action research. Journal of Epidemiological Community Health, 60, 854-857. http://dx.doi.org/10.1136/jech.2004.028662 
Bergold, J., \& Thomas, S. (2012). Participatory research methods: a methodological approach in motion. Forum Qualitative Sozialforschung / Forum: Qualitative Social Research 13(1), Art. 30.

Bessarab, D., \& Ng'andu, B. (2010). Yarning about yarning as a legitimate method in Indigenous research. International Journal of Critical Indigenous Studies, 3, 37- 50.

Bessarab, D. (2012). Yarning - A culturally safe method of Indigenous conversation. In: Dementia Networking Seminar, Perth, Australia 31 July 2012. Retrieved from: http://dtsc.com.au/wp-content/uploads/sites/2/2015/01/Dementia-Yarning-Presentation310712.pdf

Bevan, A. (2013). Creating communicative spaces in an action research study. Nurse Researcher, 21, 14-17. http://dx.doi.org/10.7748/nr2013.11.21.2.14.e347

Bishop, B.J., Vicary, D.A., Browne, A.L., \& Guard, N. (2009). Public policy, participation and the third position: the implication of engaging communities on their own terms. American Journal of Community Psychology, 43(1-2):111-21. doi:10.1007/s10464008-9214-8

Brand, A. (1990). The force of reason. An introduction to Habermas' theory of communicative action. North Sydney, NSW: Allen \& Unwin.

Braun, V., \& Clarke, V. (2006). Using thematic analysis in psychology. Qualitative Research in Psychology, 3(2), 77-101. http://dx.doi.org/10.1191/1478088706qp063oa

Campbell, N.C., Murray, E., Darbyshire, J., Emery, J., Farmer, A., Griffiths, F., Guthrie, B., Lester, H., Wilson, P., \& Kinmonth, A.L. (2007). Designing and evaluating complex interventions to improve health care. BMJ, 334, 455-459. http://dx.doi.org/10.1136/bmj.39108.379965.BE

Cohen, D., \& Crabtree, B. (2006). Qualitative research guidelines project. Retrieved from: http://www.qualres.org/HomeFocu-3647.html

Cortis, N., Katz, I., \& Patulny, R. (2009). Engaging hard-to-reach families and children. Report for the Australian Department of Families, Housing, Community Services and Indigenous Affairs. Occasional paper No 26. Canberra, Australia: Australian Department of Families, Housing, Community Services and Indigenous Affairs. Retrieved from: https:/www.dss.gov.au/sites/default/files/documents/op26.pdf

Crane, P., \& O'Regan, M. (2010). On PAR. Using participatory action research to improve early intervention. Canberra, Australia: Department of Families, Housing, Community Services and Indigenous Affairs, Australian Government. Retrieved from https://www.dss.gov.au/sites/default/files/documents/05 2012/reconnect 0.pdf

Crouch, M., \& McKenzie, H. (2006). The logic of small samples in interview based qualitative research. Social Science Information, 45, 483-499.

Davis, S.M., \& Reid, R. (1999). Practicing participatory research in American Indian communities. Am J Clin Nutr, 69(4 Suppl), 755S-759S. 
Dawson, M.C., \& Sinwell, L. (2012). Ethical and political challenges of participatory action research in the academy: reflections on social movements and knowledge production in South Africa. Social Movement Studies, 11, 177-191. http://dx.doi.org/10.1080/14742837.2012.664900

De Souza, R. (2009). Creating 'communicative spaces': a case of NGO community organising for HIV/AIDS prevention. Health Communication, 24, 692-702.

Dentith, A.M., Measor, L., \& O'Malley, M.P. (2012). The research imagination amid dilemmas of engaging young people in critical participatory work. Forum Qualitative Sozialforschung / Forum: Qualitative Social Research, 13, Art. 17. Retrieved from: http://nbn-resolving.de/urn:nbn:de:0114-fqs1201176

Denzin, N.K., \& Lincoln, Y.S. (2011). (Eds.). The Sage handbook of qualitative research $\left(4^{\text {th }}\right.$ ed). Thousand Oaks, USA: Sage.

Dudgeon, P., \& Hirvonen, T. (2014). Dark chapters in Australian history: Adopted children from the Stolen Generations. InPsych, 36(4), [Online]. Retrieved from https://www.psychology.org.au/inpsych/2014/august/dudgeon/

Dudgeon, P., Walker, R., Scrine, C., Shepherd, C., Calma, T., \& Ring, I. (2014). Effective strategies to strengthen the mental health and wellbeing of Aboriginal and Torres Strait Islander people. Report for the Closing the Gap Clearinghouse. Issues paper no. 12, November. Canberra, ACT: Australian Institute of Health and Welfare \& Melbourne and Australian Institute of Family Studies. Retrieved from: http://www.aihw.gov.au/uploadedFiles/ClosingTheGap/Content/Our_publications/2014 letgc_ip12.pdf

Fredericks, B., Adams, K., Finlay, S., Fletcher, G., Andy, S., Briggs, L., Briggs, L., \& Hall, R. (2011). Engaging the practice of Indigenous yarning in action research. ALAR Journal, 17(2), 12-24.

Geia, L.K., Hayes, B., \& Usher K. (2013). Yarning/Aboriginal storytelling: towards an understanding of an Indigenous perspective and its implications for research practice. Contemporary Nurse, 46, 13-17. http://dx.doi.org/10.5172/conu.2013.46.1.13

Grant, J., Nelson, G., \& Mitchell, T. (2008). Negotiating the challenges of participatory action research: Relationships, power, participation, change and credibility. In: R. Reason \& H. Bradbury (Eds.), The SAGE handbook of action research: participative inquiry and practice ( $2^{\text {nd }}$ ed., pp. 588-602). London, UK: Sage.

Gray, R.E., Fitch, M., Davis, C., \& Phillips, C. (2000). Challenges of participatory research: reflections on a study with breast cancer self-help groups. Health Expectations, 3, 24352.

Habermas, J. (1984). The theory of communicative action. Volume 1. Reason and the rationalisation of society. Cambridge, UK: Polity Press. 
Healey, P., White, G., Eshghi, A., Reeves, A., \& Light, A. (2008). Communication spaces. Computer Supported Cooperative Work, 17, 169-193. http://dx.doi.org/10.1007/s10606-007-9061-4

Hegney, D., \& Francis, K. (2015). Action research: changing nursing practice. Nursing Standard, 29(40), 36-41.

Henry, J., Dunbar, T., Arnott, A., Scrimgeour, M., Matthews, S., Murakami-Gold, L., \& Chamberlain, A (2002). Indigenous research reform agenda. Rethinking research methodologies. Report, Cooperative Research Centre for Aboriginal \& Tropical Health Darwin, Australia. Retrieved from: http://www.lowitja.org.au/sites/default/files/docs/IRRA2LinksMonograph.pdf

Herbert, C.P. (1996). Community-based research as a tool for empowerment: the Haida Gwaii Diabetes Project example. Can J Public Health, 87, 109-12.

Hertzman, C. (2013). The significance of early childhood adversity. Paediatric Child Health, $18(3), 127-128$.

Hunt, J. (2013). Engaging with Indigenous Australia-exploring the conditions for effective relationships with Aboriginal and Torres Strait Islander communities. Report for the Closing the Gap Clearinghouse, Issues paper 5, October. Canberra, ACT: Australian Institute of Health and Welfare \& Melbourne and Australian Institute of Family Studies. Retrieved from: http://www.aihw.gov.au/uploadedFiles/ClosingTheGap/Content/Publications/2013/ctgc -ip5.pdf

Kemmis, S., \& McTaggart, R. (1988). The action research planner (3rd ed.). Melbourne, Vic: Deakin University.

Lee, K., \& Porteous, C. (2010). Case loading: students solve their own problems using action learning. British Journal of Midwifery, 18, 603-609.

Lincoln, Y.S., \& Guba, E.G. (1985). Naturalistic inquiry. Beverly Hills, USA: Sage.

MacDougall, C. (2011). What shapes behaviours? In H. Keleher \& C. MacDougall (Eds.), Understanding health ( $3^{\text {rd }}$ ed., pp. 125-142). South Melbourne, Vic: Oxford University Press.

McDowell, T. (2015.) Applying critical social theories to family therapy practice. Springer ebook.

Mason, M. (2010). Sample size and saturation in $\mathrm{PhD}$ studies using qualitative interviews. Forum: Qualitative Social Research, 11, Art 8.

Milroy, H. (2014). Understanding the lives of Aboriginal children and families. In P. Dudgeon, H. Milroy \& R. Walker (Eds.), Working together. Aboriginal and Torres Strait Islander mental health and wellbeing principles and practice $\left(2^{\text {nd }}\right.$ ed., pp 373381). Canberra, ACT: Australian Government Department of the Prime Minister and Cabinet. 
Munns, A., \& Walker, R. (2015). The Halls Creek Community Families Program: elements of the role of the child health nurse in development of a remote Aboriginal home visiting peer support program for families in the early years. The Australian Journal of Rural Health, 23(6), 322-326. http://dx.doi.org/10.1111/ajr.12225

Munns, A., Toye, C., Hegney, D., Kickett, M., Marriott, R., \& Walker, R. (2016). The emerging role of the urban-based aboriginal peer support worker: a Western Australian study. Collegian, 23(4), 355-361. http://dx.doi.org/10.1016/j.colegn.2016.08.007

Ng'andu, B. (2004). Community workers and HIV/AIDS: stories from Botswana. Women in Welfare Education, 7, 118-126. Retrieved from

http://www.anzswwer.org/download/WIWE_07_2004.pdf

Pihama, L., Reynolds, P., Smith, C., Reid, J., Smith, L.T., \& Te Nana, R. (2014). Positioning historical trauma theory within Aotearoa New Zealand. AlterNative: An International Journal of Indigenous Peoples, 10(3), 248-262

Polit, D., \& Beck, C. (2010). Essentials of nursing research (7th ed.). Philadelphia, USA: Lippincott Williams and Wilkins.

Pyett, P. (2002). Working together to reduce health inequalities: reflections on a collaborative participatory approach to health research. Aust N Z J Public Health, 26, 332-6.

Queensland Government, Department of Communities (DoC) (n.d.). Engaging Queenslanders: A guide to community engagement methods and techniques. Report, Queensland Government, Australia. Retrieved from: https://www.qld.gov.au/web/community-engagement/guidesfactsheets/documents/engaging-queenslanders-methods-and-techniques.pdf

Rath, J. (2012). Poetry and participation: scripting a meaningful research text with rape crisis workers. Forum Qualitative Sozialforschung / Forum: Qualitative Social Research, 13, Art. 22. Retrieved from: http://nbn-resolving.de/urn:nbn:de:0114-fqs1201224

Redman-MacLaren, M., \& Mills, J. (2015). Transformational grounded theory: theory, voice and action. International Journal of Qualitative Methods, 14, online. Retrieved from: http://ejournals.library.ualberta.ca/index.php/IJQM/article/view/21771/18671

Rix, E.F., Barclay, L., \& Wilson, S. (2014). Can a white nurse get it? 'Reflexive practice" and the non-Indigenous clinician/researcher working with Aboriginal people. Rural and Remote Health, 14, 2679. Retrieved from: http://www.rrh.org.au

Roberts, G., \& Dick, B. (2003). Emancipatory design choices for action research practitioners. Journal of Community and Applied Social Psychology, 13, 486-95. http://dx.doi.org/10.1002/casp.753

Roberts, K., \& Taylor, B (2002). Nursing research process: an Australian perspective (2nd ed.). Melbourne, Vic: Nelson.

Roer-Strier, D., \& Sands, R.G. (2015). Moving beyond the 'official story': when 'others' meet in a qualitative interview. Qualitative Research, 15, 251-268. 
Rosenthal,W.A., \& Khalil, D.D. (2010). Participatory action research in the context of HIV and poverty. Curationis, 33, 69-78.

Sanson-Fisher, R.W., Campbell, E.M., Perkins, J.J., Blunden, S.V., \& Davis, B.B. (2006). Indigenous health research: a critical review of outputs over time. MJA, 184, 502-505. Retrieved from https://www.mja.com.au/system/files/issues/184_10_150506/san10764_fm.pdf

Schaffer, M.A., Keller, L.O., \& Reckinger, D. (2015). Public health nursing activities: visible or invisible? Public Health Nursing, 32(6), 711-20. http://dx.doi.org/10.1111/phn.12191

Smith, P.A.C., \& O’Neil, J. (2003). A review of action learning literature 1994-2000: Part 1 - Bibliography and comments. Journal of Workplace Learning, 15, 63-69. http://dx.doi.org/10.1108/13665620310464102

Smith, L.J. (2005). On tricky ground: researching the native in the age of uncertainty. In N.K. Denzin \& Y.S. Lincoln (Eds.), The Sage handbook of qualitative research $\left(3^{\text {rd }} \mathrm{ed} ., \mathrm{pp}\right.$. 85-107). Thousand Oaks, CA: Sage.

Snijder, M., Shakeshaft, A., Wagemakers, A., Stephens, A., \& Calabria, B. (2015). A systematic review of studies evaluating Australian indigenous community development projects: the extent of community participation, their methodological quality and their outcomes. BMC Public Health, 15, 1154 http://dx.doi.org/10.1186/s12889-015-2514-7

Spurell, M. (2000). Consultant learning groups in psychiatry. Report on a pilot study. Psychiatric Bulletin, 24, 390-392. http://dx.doi.org/10.1192/pb.24.10.390

Strubert-Speziale, H.S., \& Carpenter, D.R. (2003). Qualitative research in nursing: advancing the humanistic imperative. Philadelphia, USA: Lippincott Williams and Wilkins.

Sullivan, E., Hegney, D., \& Francis, K. (2013). An action research approach to practice, service and legislative change. Nurse Researcher, 21, 8-13.

http://dx.doi.org/10.7748/nr2013.11.21.2.8.e330

Susman, G., \& Every, R. (1978). An assessment of the scientific merits of action research. Administrative Quarterly, 23, 582-603. http://dx.doi.org/10.2307/2392581

Turner, C. (2002). Action research and better outcomes for community projects. Stronger Families Learning Exchange Bulletin, 2(Spring/Summer), 6-7. Retrieved from: http://citeseerx.ist.psu.edu/viewdoc/download?doi=10.1.1.199.7061\&rep=rep1\&type=pd $\mathrm{f}$

Wilson, D., \& Neville, S.J. (2009). Culturally safe research with vulnerable populations. Contemporary Nurse, 33(1), 69-79. doi: 10.5172/conu.33.1.69

Wright, M. (2011). Research as intervention: Engaging silenced voices. ALAR Journal, 17(2), $25-46$ 
Zubrick, S.R., Shepherd, C., Dudgeon, P., Gee, G., Paradies, Y., Scrine, C., \& Walker, R. (2014). Social determinants of social and emotional wellbeing. In P. Dudgeon, H. Milroy \& R. Walker (Eds.), Working together. Aboriginal and Torres Strait Islander mental health and wellbeing principles and practice ( $2^{\text {nd }}$ ed., pp. 93-112). Canberra: Australian Government Department of the Prime Minister and Cabinet. 


\section{Appendix A}

\section{Interview questions}

\section{Peer support workers}

1. Unstructured question: Tell me about the program and how you see it is going?

2. Semi-structured questions:

- Think about your visits - what is working well? How are these visits encouraging and supporting parents?

- What is not working well? Why do you think this is happening?

- How could you have said things differently that allowed parents time to talk and work on their ideas?

- Have you had any visits where the problems have been too hard to handle?

\section{Client families}

Unstructured question:

- Can you tell me about the program and the Parent Support Worker who is coming to see you?"

\section{Community agencies}

Semi-structured questions:

- Can you tell me about the program and how you see it is helping or not helping parents in [this area]?

- Can we work together more collaboratively?" 